\section{A Rare Case of a Symptomatic Sternalis Muscle: Ultrasonograpy And MRI Correlation}

\section{Introduction \\ $\nabla$}

Accessory muscles are common, yet often overlooked entities (Sookur PA et al. Radiographics 2008, 2: 481-499) and are most often found in the extremities. While frequently just an incidental finding in radiological examinations like ultrasound or MRI or during autopsy, there are incidences of symptomatic accessory muscles due to muscular imbalances, overuse tendinopathies, presentation as a soft tissue mass (López Milena G et al. Eur. Radiol. 2001, 8: 1487-1489), vascular (Sookur PA et al. Radiographics 2008, 2: 481-499) or neural compression syndromes (Sookur PA et al. Radiographics 2008, 2: 481-499; Paraskevas G et al. Clin. Anat. 2008, 3: 246-251; Kinoshita M et al. Foot ankle Int. 2003, 2: 132-136).

While most case reports and case series describe accessory muscles of the extremities (Sookur PA et al. Radiographics 2008, 2: 481-499; Paraskevas G et al. Clin. Anat. 2008, 3: 246-251; Christodoulou A et al. Br. J. Sports Med. 2004, 6: e38; López Milena G et al. Eur. Radiol. 2001, 8: 14871489; Paraskevas GK and Ioannidis O Ital. J. Anat. Embryol. 2011, 1: 45-51; Howe BM and Murthy NS J. Radiol. Case Rep. 2012, 10: 20-25; Kouvalchouk JF et al. Rev. Chir. Orthop. Reparatrice Appar. Mot. 2005, 232-238; Kinoshita M et al. Foot Ankle Int. 2003, 2: 132-136), there are only a few reports on accessory muscles of the thorax. While variations of the pectoral muscles (Natsis $\mathrm{K}$ and Totlis T Clin. Anat. 2007, 8: 980-981; Huntington GS J. Anat. Physiol. 1904, Pt 1: 1-54.27) and intercostal muscles (Nelson ML et al. Anat. Rec. 1992, 2: 318-321) often remain without clinical symptoms, accessory muscles of the upper thorax aperture and neck can cause symptoms, such as thoracic outlet syndrome (Singhal S, Vijaya Rao V and Manjunath KY Int. J. Morphol. 2008, 4: 813-815; Forcada P et al. Clin. Anat. 2001, 1: 55-57).

The sternalis muscle has a long history of scientific publications (Snosek M, Tubbs RS and Loukas M Clin. Anat. 2014, 6: 866884) describing this common variant

\section{License terms}

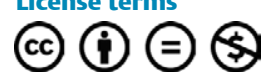
through sonopalpation along the muscle.
Clin. Anat. 2003, 4: 350-354) or as an incidental finding mainly during mammography (Scott-Conner CEH et al. Clin. Anat. 2002, 1: 67-69) or surgery (Bailey PM et al. Plast. Reconstr. Surg. 1999, 4: 11891190). However, to our knowledge, there is no report of a sternalis muscle with clinical symptoms and dedicated sonographic workup.

\section{Case Description \\ $\nabla$}

A 51-year-old female patient with a history of rheumatoid arthritis was referred to exclude synovitis and enthesitis due to right parasternal swelling, which was described as painful upon application of pressure, and respiratory excursion of the thorax. These symptoms had begun several months ago and slowly increased in intensity. Inspection revealed slight asymmetry with a right parasternal volume increase. Palpation was described as painful. No other asymmetries were apparent.

Ultrasound (performed on a Logiq E9 with a GL6-15 linear transducer; GE Healthcare; Milwaukee, WI, USA) revealed a unilateral right parasternal muscle-isoechoic structure extending from above the sternal manubrium along the lateral edge of the sternal corpus to the lower costosternal joints ( $\boldsymbol{0}$ Fig. 1a, b). The fiber orientation was axial. An in- crease in vascularity, surrounding fluid and costosternal synovitis/effusion could not be detected. Sonopalpation confirmed the structure to be the origin of the described pain.

Detailed findings could be achieved via MRI (Siemens Skyra 3T; Siemens, Erlangen): the structure demonstrated muscle-isointense signal properties and was embedded in fat. No fluid collections, nodular areas or edema was present. It originated from the anterior aspect of the sternoclavicular joint, ran along the right sternal edge just above the fibers of the major pectoral muscle and ended at the $5^{\text {th }}$ costal cartilage. Its axial length was $170 \mathrm{~mm}$ with a diameter of $21 \times 8 \mathrm{~mm}$. In its lower third a common partial fascia with the major pectoral muscle was observed. Asymmetry of the medial muscle fibers of the ipsilateral major pectoral muscle was present ( $\bullet$ Fig. $\mathbf{2 a}, \mathbf{b}, \mathbf{c}$ ).

\section{Discussion \\ $\nabla$}

First described in 1604 by Cabrolio, the sternalis muscle shows a high prevalence of ca. 3-11\% (Arráez-Aybar LA et al. Clin. Anat. 2003, 4: 350-354; Scott-Conner CEH et al. Clin. Anat. 2002, 1: 67-69; Snosek M et al. Clin. Anat. 2014, 6: 866884). It is a small band-like muscular structure with axial orientation superficial to the pectoral fascia (Scott-Conner CEH et al. Clin. Anat. 2002, 1: 67-69). It may be an embryonic remnant of the rectus muscle (Arráez-Aybar LA et al. Clin. Anat. 2003, 4: 350-354) or a derivate from the pectoralis muscle (Kida MY et al. Clin. Anat. 2000, 2: 138-140). The muscle
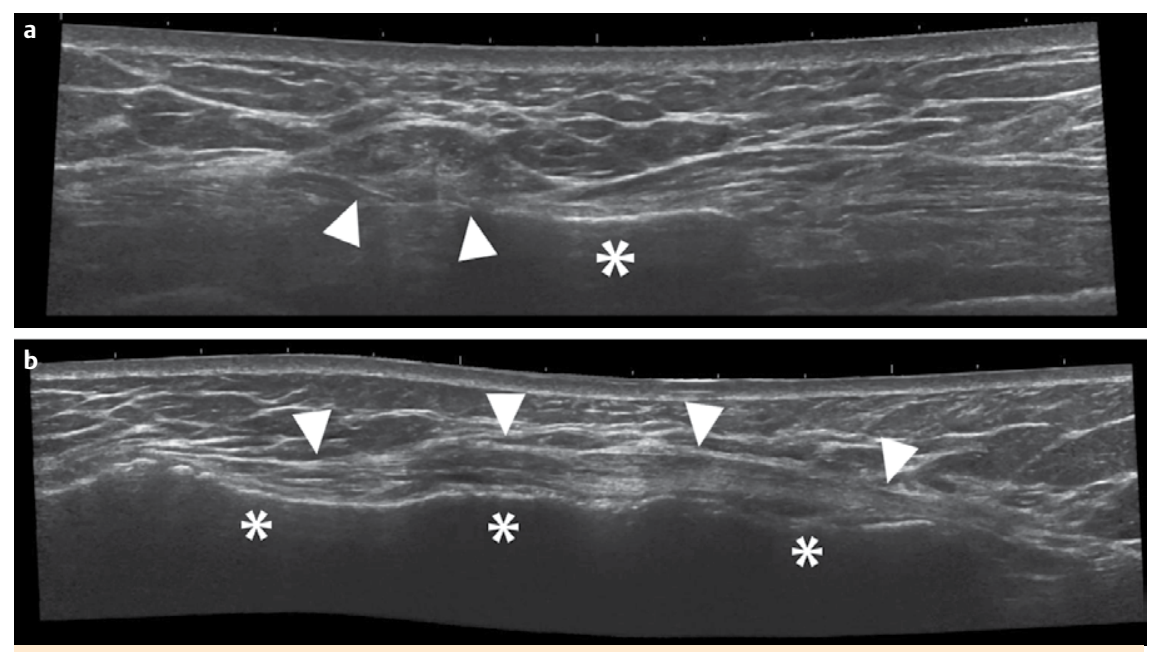

Fig. 1 Axial a and longitudinal b panoramic ultrasound images of the sternalis muscle (white arrowheads). Sternum $\left({ }^{*}\right)$. A painful sensation comparable to the primary symptoms could be provoked 

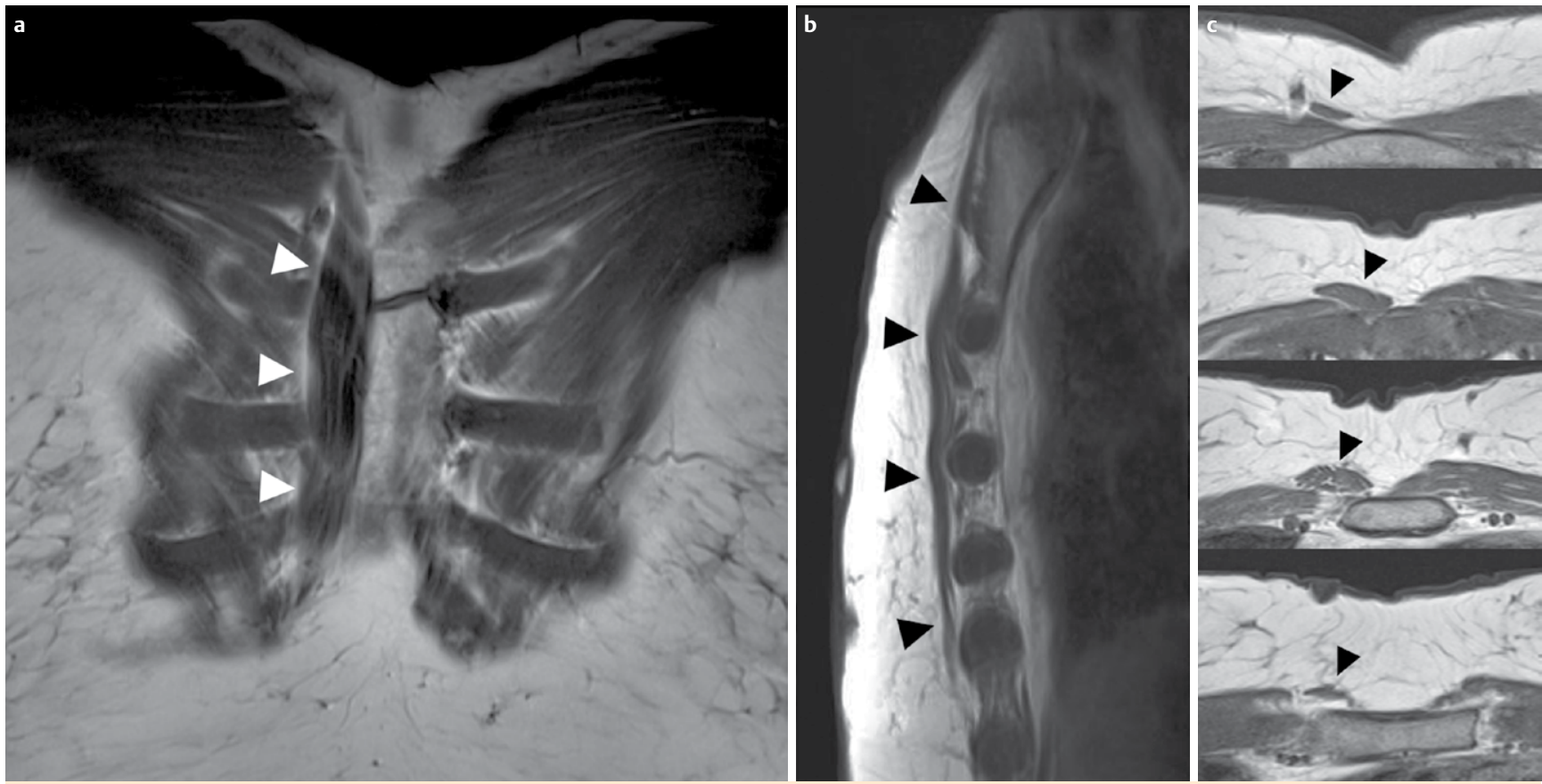

Fig. 2 Corresponding coronal a, longitudinal $\mathbf{b}$ and axial $\mathbf{c}$ T1w MRI studies of the sternalis muscle (arrowheads). $\mathbf{a}$ is a composite image of 3 coronal slices ( $3 \mathrm{~mm}$ slice thickness, TE $20 \mathrm{~ms}$, TR $797 \mathrm{~ms}$ ), while b demonstrates the sagittal extent (MIP $7.5 \mathrm{~mm}$; TE $20 \mathrm{~ms}$, TR $812 \mathrm{~ms}, 3 \mathrm{~mm}$ slice thickness of original study). Note the superficial marker placed at the site of the highest pain intensity by the patient. c shows 4 axial slices in the cranio-caudal sequence (TE $21 \mathrm{~ms}$, TR $804 \mathrm{~ms}, 4 \mathrm{~mm}$ slice thickness).

is believed to cause no symptoms besides asymmetry and to our knowledge there are no reports on clinical symptoms. This may be due to the nature and location of the muscle, but also due to low clinical awareness (Arráez-Aybar LA et al. Clin. Anat. 2003, 4: 350-354).

We present a highly unusual case of a clinically symptomatic sternalis muscle in a female patient. The described pain upon pressure or respiratory excursion of the thorax may stem from muscular imbalance, as there was significant hypoplasia of the pectoral muscle fibers compared to the contralateral non-affected side. Parasternal asymmetry has been described before (Scott-Conner CEH et al. Clin. Anat. 2002, 1: 67-69; O'Neill MN et al. J. Anat. 1998, Pt 2: 289-292). Possibly a unilateral lack of pectoral muscle mass may lead to muscular imbalances and a compensatory increase in tension of the remaining fibers with potential mild inflammation at the fiber insertion. The sternalis muscle itself may also exert contractile vertical force along the costosternal joints. Alternatively, compression of anterior cutaneous branches of the lateral pectoral nerve or of intercostal nerves could be causative as anatomical studies have shown that branches from both nerves can run through the sternalis muscle (Kida MY et al. Clin. Anat. 2000, 2: 138-140; Snosek M et al. Clin. Anat. 2014, 6: 866-884).

\section{Conclusion \\ $\nabla$}

While most often clinically silent, the presence of a sternalis muscle should be considered when patients describe longterm painful soft tissue swelling of the parasternal region. Ultrasonography is a valuable tool to confirm the presence of a sternalis muscle.

L. Gruber, C. Martinoli, A. S. Tagliafico,
J. Gruber, A. S. Klauser 